\title{
Metal Phase Formation in Bubbling Reduction of Nickel and Iron from Oxide Melt
}

\section{Alexander Semenovich Vusikhis, Leopold Igorevich Leontyev, Victor Pavlovich Chentsov, and Evgeny Nicolaevich Selivanov}

Institute of Metallurgy of the Ural Branch of the Russian Academy of Sciences, 620016, Yekaterinburg, Amundsen st., 101

\section{Abstract}

Bubbling reduction of nickel and iron from oxide melt is considered. Oxidized nickel ores melts interaction with gases (hydrogen, carbon monoxide, converted natural gas) is accompanied by the ferroalloy formation with high nickel content. This process is associated with the mass transfer, chemical reaction running and metal phase formation in the multi-component oxide melts, regardless of the reducing agent used. Those processes are of great importance for understanding of the ferronickel pyrometallurgical production processes. To describe the process, we used equations

Corresponding Author:

Alexander Semenovich Vusikhis vas58@mail.ru

Received: 5 February 2019

Accepted: 6 March 2019

Published: 17 March 2019

Publishing services provided by Knowledge E

(c) Alexander Semenovich

Vusikhis et al. This article is

distributed under the terms of

the Creative Commons.

Attribution License, which

permits unrestricted use and

redistribution provided that the

original author and source are credited.

Selection and Peer-review under the responsibility of the NIOKR-2018 Conference Committee. that allow one to estimate the size of gas bubble and metal drop moving in an oxide melt without fragmentation, its joint movement direction, flotation rate, sedimentation and separation conditions. The physicochemical characteristics affecting mass transfer (the densities and surface tensions of oxide and metal melts, as well as their interfacial characteristics) have been determined.

Keywords: nickel, iron, reduction, bubbling, metal, oxide, melts, ores, ferroalloy, flotation, sedimentation, reducing gas

\section{Introduction}

Oxidized nickel ores melts interaction with gases (hydrogen, carbon monoxide, converted natural gas) is accompanied by the ferroalloy formation with high nickel content. This process is associated with the mass transfer, chemical reaction running and metal phase formation in the multi-component oxide melts, regardless of the reducing agent used. Those processes are great importance for understanding of the ferronickel pyrometallurgical production processes. In the previous works [1, 2], a model was proposed for the metal phase formation during bubbling of an oxide melt by a reducing gas, which includes following stages: formation of bubbles during the gas injection into the melt; metal reduction at the gas-melt interface; metal droplets formation; movement of 
of the acting gravitational forces; transfer of metal droplets to the surface, its coalescence and sedimentation after reaching the dimensions ensuring gravity excess over the sum of hydrostatic extrusion and surface tension forces. To describe the process, we used equations that allow one to estimate the size of gas bubble and metal drop moving in an oxide melt without fragmentation, its joint movement direction, flotation rate, sedimentation and separation conditions. The physicochemical characteristics affecting mass transfer (the densities and surface tensions of oxide and metal melts, as well as their interfacial characteristics) have been determined. The density and surface tension of ferronickel melts (Figure 1) and oxidized nickel ore containing \%: $14.8 \mathrm{Fe}_{\text {total }}, 7.1 \mathrm{FeO}$, 13.2 $\mathrm{Fe}_{2} \mathrm{O}_{3}, 1.4 \mathrm{CaO}, 16.2 \mathrm{MgO}, 54,5 \mathrm{SiO}_{2}, 4.8 \mathrm{Al}_{2} \mathrm{O}_{3}, 1.5 \mathrm{NiO}, 1.2 \mathrm{Cr}_{2} \mathrm{O}_{3}$ (Figure 2), as well as interfacial tension at its boundary (Figure 3 ) in the temperature range 1550-1750 ${ }^{\circ} \mathrm{C}$. Functional dependencies connecting density, surface and interfacial tensions with temperature and composition of melts have the form:

$$
\begin{gathered}
\rho_{1}=\left[\left(6996+6.7 C_{N i}\right]-\left[0.83+0.0004 C_{N i}\right](t-1550),\right. \\
\sigma_{1}=\left[0.0059 C_{N i}{ }^{2}-1.1432 C_{N i}+1770\right]-\left[0.0002 C_{N i}{ }^{2}-0.024 C_{N i}+0.96\right](t-1550), \\
\rho_{2}=2247-2.1(t-1550), \\
\sigma_{2}=310-0.1(t-1550), \\
\sigma_{12}=\left[0.0069 C_{N i}{ }^{2}-1.2727 C_{N i}+1650\right]-\left[0.0002 C_{N i}{ }^{2}-0.024 C_{N i}+0.96\right](t-1550)
\end{gathered}
$$

the parameters: $\rho_{1}, \rho_{2}, \sigma_{1}, \sigma_{2}$ are density and surface tension of the metal and oxide melt, respectively; $\sigma_{12}$ is the interfacial tension at its boundary.

The critical dimensions of gas bubble and metal droplet (moving in oxide melt without fragmentation), the maximum sizes of metal droplets forming on single bubble when nickel and iron are reduced from the oxide melt are determined using the obtained data. The flotation condition dependencies on sizes of the "gas bubble - metal drop" - system are determined too.

The maximum radius of the bubble $\left(R_{b}^{m}\right)$, floating up in the melt without fragmentation, is determined by the equation [3]:

$$
R_{b}^{m}=\left(3 / k_{f}\right)^{1 / 3} \sigma_{2} w_{b}^{-2} \rho_{g}^{-1 / 3} \rho_{2}^{-2 / 3},
$$

where $w_{b}$ is the speed of the bubble rise $(\mathrm{m} / \mathrm{s}) ; k_{f}$ is the resistance coefficient; $\rho_{2}, \rho_{g}$ are the melt and gas density, respectively $\left(\mathrm{kg} / \mathrm{m}^{3}\right)$. Taking $k_{f}$ close to unity and $w_{g}=$ $\sqrt[4]{4 g \sigma / k_{f} \rho_{2}}$ [4], we get equation

$$
R_{b}^{m}=0.72 \sigma_{2}^{1 / 2} \rho_{2}^{-1 / 6} \rho_{g}^{-1 / 3} g^{-1 / 2} .
$$



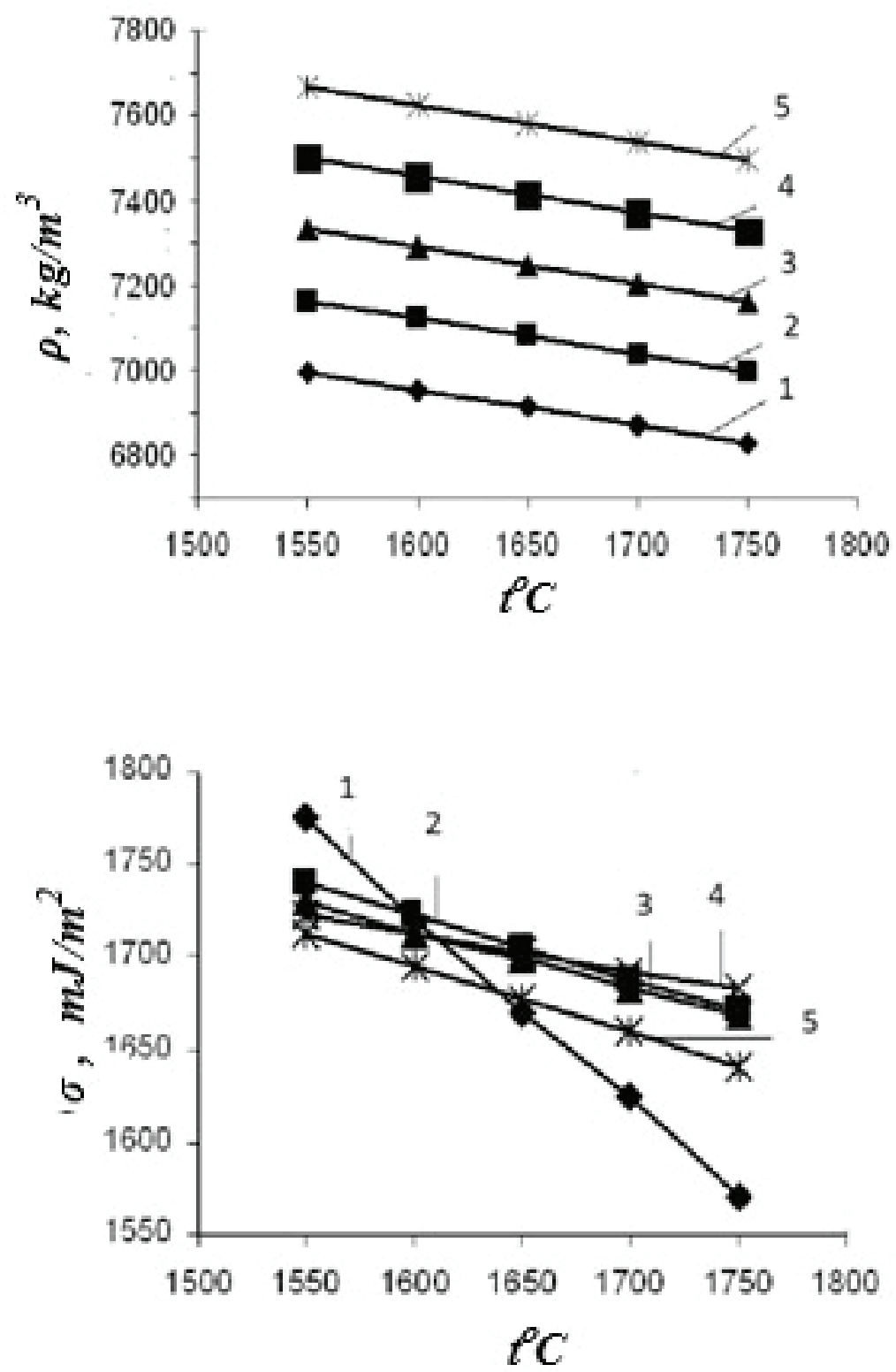

Figure 1: Density $\left(\rho_{1}\right)$ and surface tension $\left(\sigma_{1}\right)$ temperature dependencies of an iron-nickel melt: 0 (1), 25 (2), 50 (3), 75 (4), 100 (5) \% Ni in the alloy.

In the temperature range $1550-1750{ }^{\circ} \mathrm{C}$, the values change slightly (Figure 4 ) and increase from $6.35 \cdot 10^{-2} \mathrm{~m}$ (at $1550 \mathrm{C}$ ) to $6.58 \cdot 10^{-2} \mathrm{~m}$ (at $1750 \mathrm{C}$ ). Maximum radius of the metal droplets $\left(r_{d}^{m}\right)$, which are in the slag without fragmentation, is determined by the equation [3]

$$
r_{d}^{m}=0.9 k_{f}^{\frac{1}{2}} \sigma_{12}^{\frac{1}{2}} \rho_{2}^{\frac{2}{3}} \rho_{1}^{-\frac{1}{3}}\left(\rho_{1}-\rho_{2}\right)^{-\frac{5}{6}} g^{-\frac{1}{2}}
$$

The $r_{d}^{m}$ parameter depends on the droplet composition and temperature and varies from $2.1 \cdot 10^{-3}$ to $2.9 \cdot 10^{-3}$ (Figure 4 ). 


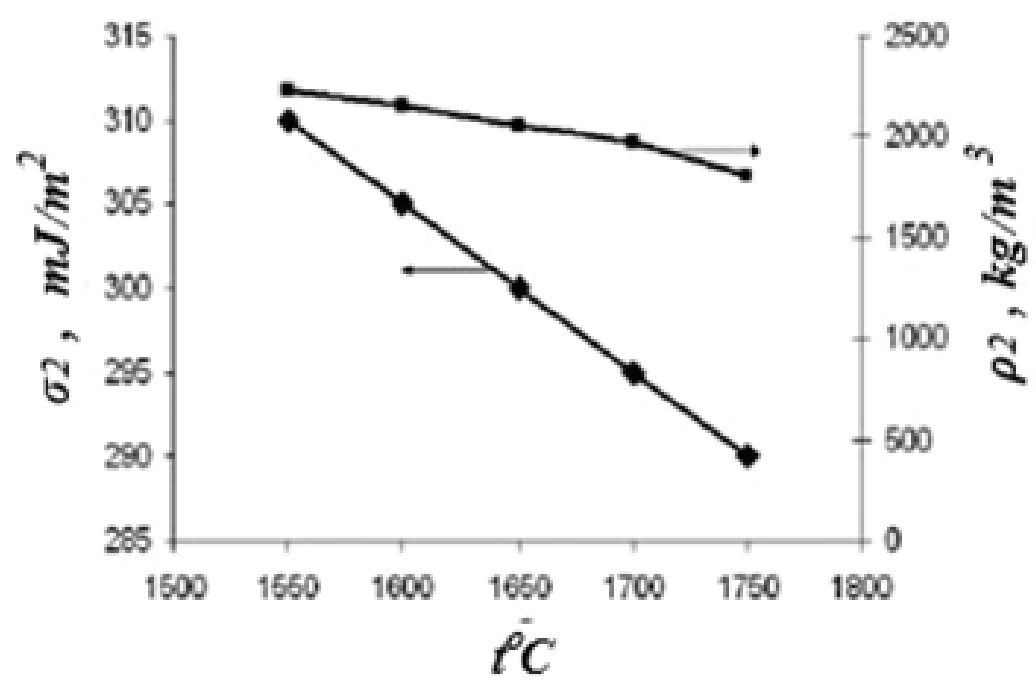

Figure 2: Surface tension $\left(\sigma_{2}\right)$ and density $\left(\rho_{2}\right)$ temperature dependencies of the oxide melt.

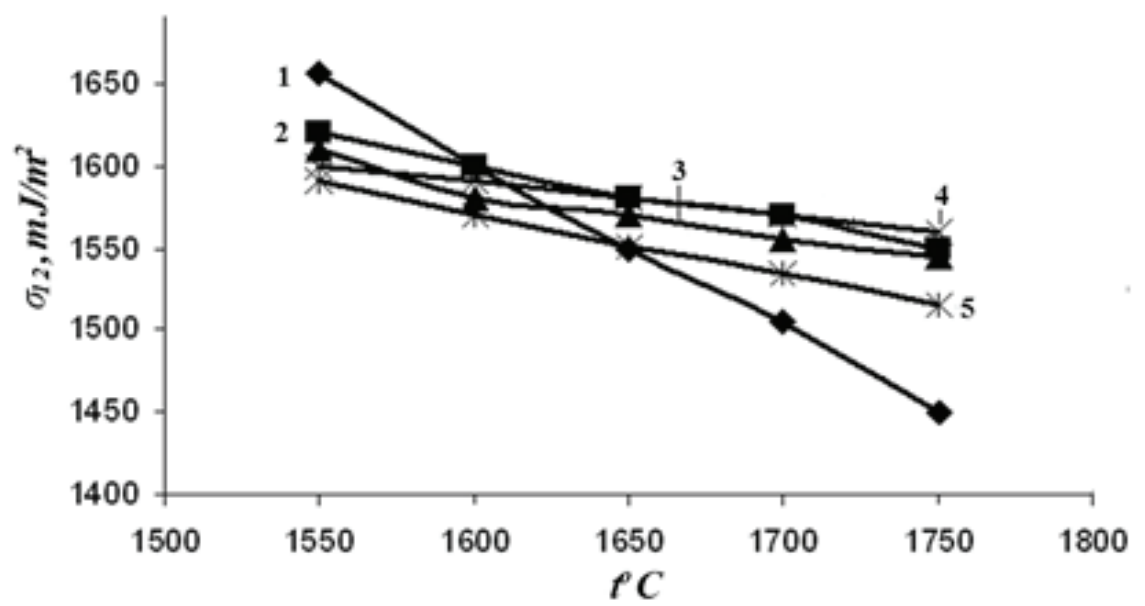

Figure 3: Interfacial tension temperature dependencies $\left(\sigma_{12}\right)$ at the interface of oxide melts and alloys containing 0 (1), 25 (2), 50 (3), 75 (4), 100 (5) \% Ni.

The size of metal drop formed on single bubble during the Nickel and Iron reduction from the oxide melt composition under consideration is determined by calculating the thermodynamic equilibrium describing the kinetics of bubbling by reducing gases [5]. As the content of nickel and iron oxides in the melt decreases due to the metals reduction, the nickel content of ferronickel drops decreases from 89 to $18 \%$, and its diameters decrease from $1 \cdot 4 \cdot 10^{-3}$ to $8.0 \cdot 10^{-4} \mathrm{~m}$. At the same time the metal drop mass decreases from $9.4 \cdot 10^{-5}$ to $1.6 \cdot 10^{-5} \mathrm{~kg}$. Taking into account the obtained data, the flotation conditions of the "gas bubble - metal drop" system depending on its sizes are formulated. Gas flotation of metal particles in the oxide melt occurs if the gravity of the droplet $\left(F_{d}\right)$ is less than the bubble lifting force $\left(F_{b}\right)$ that is $\left(F_{d}<F_{b}\right)$, while $r_{d} / R_{b}<\left[\rho_{2} /\left(\rho_{1}-\rho_{2}\right)\right]^{1 / 3}$. In this case, when ferronickel droplet comes in contact with $\mathrm{CO}-\mathrm{CO}_{2}$ bubble, this ratio 

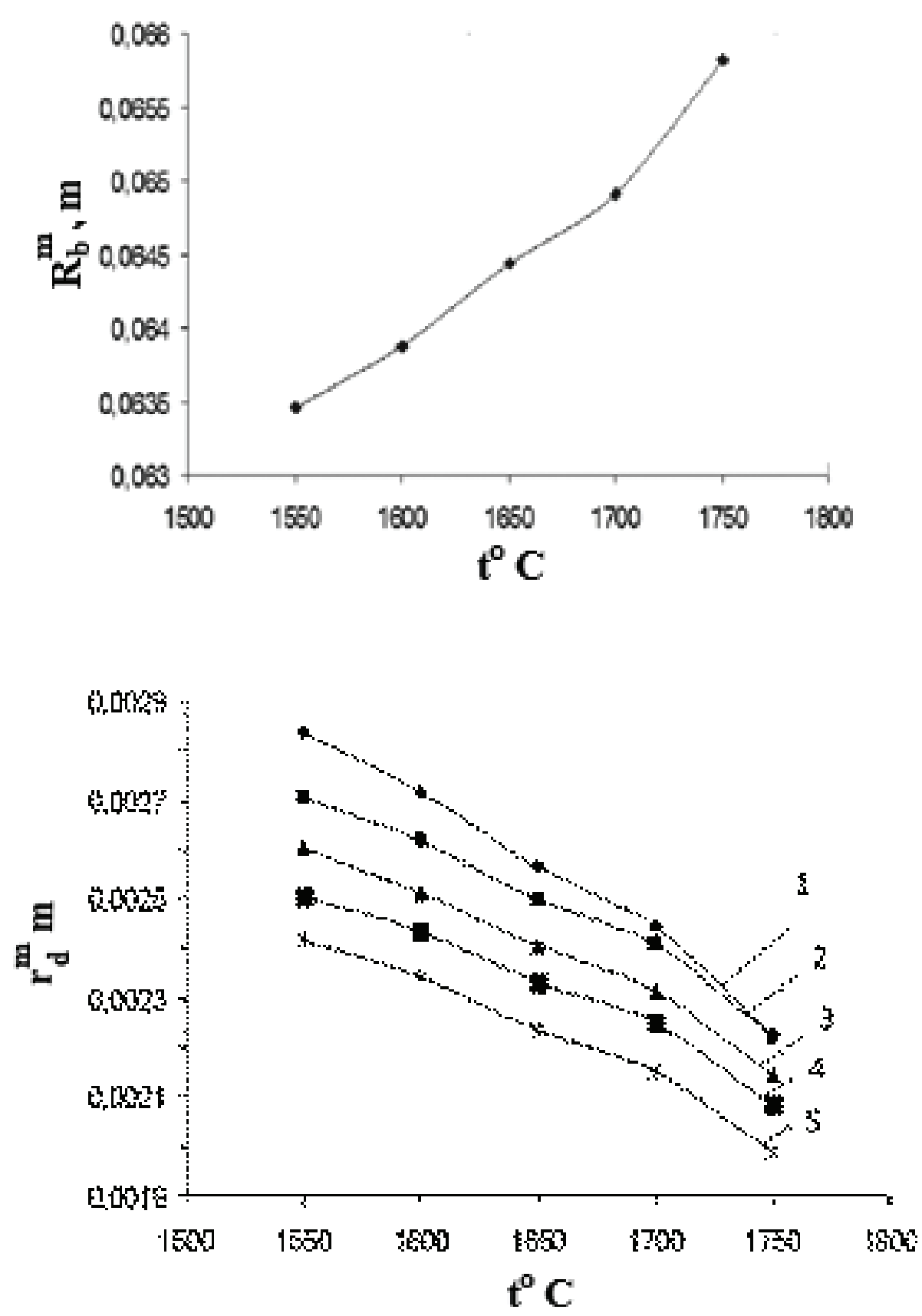

Figure 4: Temperature dependence of the gas bubble critical radii (a) and ferronickel drops (b), containing: 0 (1), 25 (2), 50 (3), 75 (4), 100 (5) \% Ni.

depends on the Nickel alloy content and temperature. In the considered temperature ranges and the contents of Nickel and Iron, the "CO bubble-metal drop" system floats in the oxide melt when the $r_{d} / R_{b}$ ratio is less than $0.68-0.78$. To estimate the system "CO bubble-metal drop" stability with the above bubble and a drop dimensions, the parameters determining their joint movement were calculated. The presented system existence is possible as long as the forces ensuring the fixation of metal drop on gas 


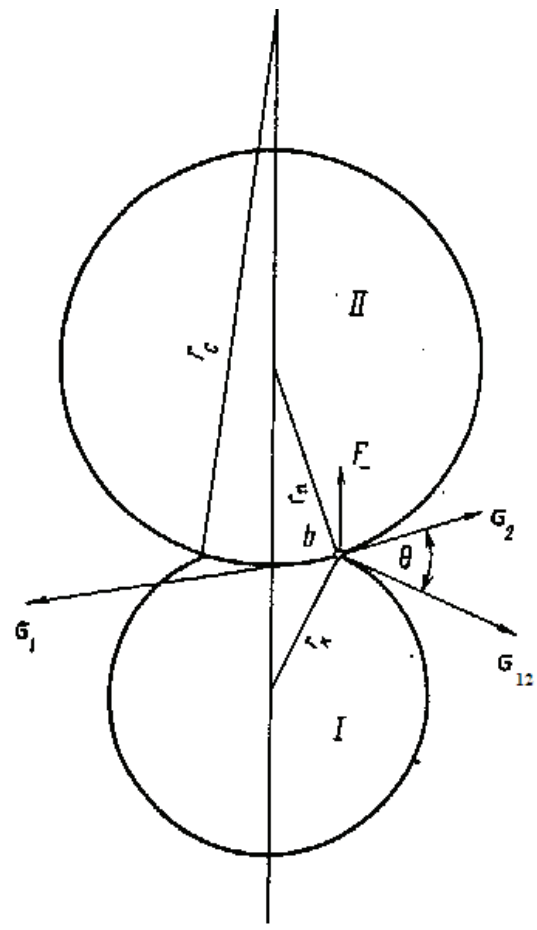

Figure 5: The scheme of metal drop (I) fixing on gas bubble (II).

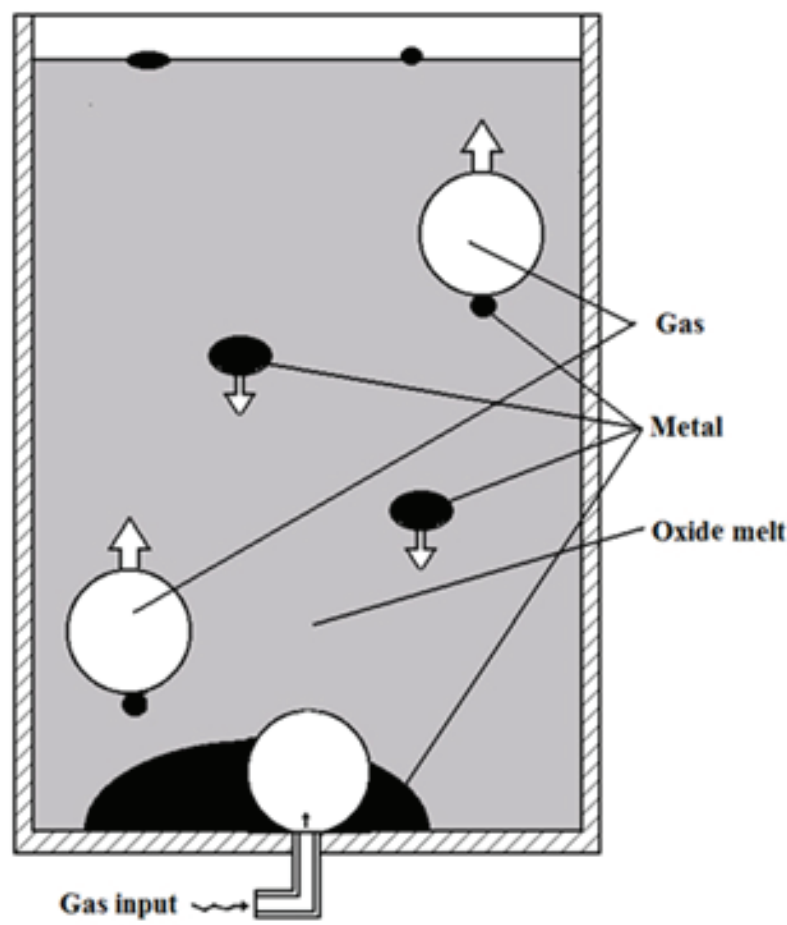

Figure 6: The scheme of metal phase formation in oxide melt bubbling.

bubble exceed the forces intended to break this bond. The force holding drop on bubble $\left(F_{\sigma}\right)$ is defined as the algebraic sum of the surface tension forces projections on the 
vertical axis (Figure 5) multiplied by the length of drop and bubble contact perimeter [6], according to (9) equation:

$$
F_{\sigma}=2 \pi r_{K} \sigma_{1} \sin (0.5 \Theta+M)\{m[\sin (0.5 \Theta-M)+\sin (0.5 \Theta+M)]-n \sin (0.5 \Theta-M)
$$

where $M=\operatorname{arctg}\left(\frac{r-r}{r+r} \operatorname{tg} 0.5 \Theta\right), \mathrm{m}=\sigma_{12} / \sigma_{1}, \mathrm{n}=\sigma_{2} / \sigma_{1}$. Angle $\Theta$ (between $\sigma_{2} и \sigma_{12}$ ) was taken according to (8) equality (the surface tension forces projection on horizontal axis to zero):

$$
n \cos (0.5 \Theta-M)+m \cos (0.5 \Theta+M)-\cos \{\arcsin [m \sin (0.5 \Theta-M)]\}=0
$$

Expression (8) is valid for $\left|\frac{1-n}{B}\right| \leq 1$. Thus, angle $\Theta$ obviously depends not only on the interfacial forces, but also on the bubble and drop sizes ratio. The following calculation: $\Theta$ - angles, drop $\left(r_{k}\right)$ and bubble $\left(R_{b}\right)$ radii, its ratio $\left(r_{k} / R_{b}\right)$ were carried out. Those results define the bubble-drop system disconnection, separation forces, as the algebraic sum of the drop gravity $\left(F_{g}\right)$, surface tension $\left(F_{\sigma}\right)$, gas bubble size, surface tension forces $\left(F_{\sigma}\right)$ and $F_{g} / F_{\sigma}$ ratio, with drop radius $r_{d}=2.4 \cdot 10^{-3} \mathrm{~m}$ and its gravity $3 \cdot 1 \cdot 10^{-4} \mathrm{~N}$ showed that the metal drop from gas bubble separation is not possible under the conditions, realized in pyrometallurgical units processes. When $R_{b}$ and $r_{d}$ are less than critical values, the "CO bubble- metal drop" system is not separated in the oxide melt and floats to the surface where the gas bubble is destroyed and the metal drop remains on the surface. Taking into account the data obtained, the metal phase forming process as a result of nickel and iron bubbling reduction by carbon monoxide (Figure 6) is described, which consists in the following. The oxide melt interaction with the gas is accompanied by the metal droplets formation, which, being fixed on the bubbles, move to the oxide melt surface. The metal of $80-90 \% \mathrm{Ni}$ content is formed initially, but as the nickel fraction in the oxide melt decreases, its content in metal drops decreases to $20 \%$. On the oxide melt surface, metal droplets merge and, when reaching a size of more than $5 \cdot 10^{-3} \mathrm{~m}$, "brake" the surface and sink to the bottom. In the case of metal drop collisions with the gas bubbles and drops attached rising towards them, they merge or flow around. When merged, small drops will be assimilated and raised to the surface. The force of drop from bubble detachment significantly exceeds the droplets gravity force, therefore drop the "bubble - metal drop" system is stable for all its sizes ratios considered.

Thus nickel and iron by carbon monoxide reduction bubbling, as follows from the data obtained, the metal droplets formed are moving to the oxide melt surface together with gas bubbles. The metal droplets, the size of which depends on the single bubble size, merge on the surface, and sink to the bottom, forming the bottom phase. In the initial period, a metal bottom phase can be formed with $70-80 \% \mathrm{Ni}$, which is further diluted with a metal with lower nickel content. 
The proposed method allows us to estimate the bubbling processes parameters for various types of raw materials and to predict its processing efficiency.

\section{References}

[1] A.S.Vusikhis. The formation of the metal phase during sparging gas-reducing multicomponent oxide melts. Communication 1. Theoretical bases of the process / A.S.Vusikhis, L.I.Leontyev, V.P.Chentsov, D.Z.Kudinov, E.N.Selivanov // News of the Universities. Black Metallurgy, 2016, №9, p. 639-644.

[2] A.S.Vusikhis. The formation of the metal phase during sparging gas-reducing multicomponent oxide melt. Communication 3. Separation of ferronickel and oxide melt / A.S.Vusikhis, L.I.Leontyev, V.P. Chentsov, D.Z.Kudinov, E.N. Selivanov //. News of the Universities. Ferrous metallurgy. 2017; No. 12, C. 960-965.

[3] Yu.A.Minaev Physical chemistry in metallurgy / Yu.A. Minaev, V.V. Yakovlev // M. MISIS, 2001. - 320 p.

[4] V.G. Baryshnikov. Kinetic features of the sedimentation of metallic inclusions in slags. / V.G.Baryshnikov, A.A.Deryabin, S.I.Popel, M.I.Panfilov // Izv.AN USSR, Metals, 1970, № 2, p.106-115.

[5] A.S.Vusikhis. The study of liquid and gas phases interaction during the reduction of metal oxides from the melts by gas reluctant in bubbled layer / A.S.Vusikhis, A.N.Dmitriev, D.Z.Kudinov, L.I.Leontiev.//The Third International Conference on Mathematical Modeling and Computer Simulation of Materials Technologies (MMT-2004), Ariel, Israel. 2004, P. 1_72-77.

[6] A.A. Kazakov. Analysis of droplet flotation conditions in steelmaking processes / A.A. Kazakov // Metals, No. 6, 1990, p. 13-18.

The work was carried out as part of the state assignment of IMET Ural Branch of the Russian Academy of Sciences on the subject No. 0396-2015-0082 